\title{
No Longer on Speaking Terms: The Losses Associated With Family Estrangement at the End of Life
}

Kylie Agllias

\begin{abstract}
Family estrangement is the physical distancing and loss of affection between family members, often due to intense conflict or ongoing disagreement. While the concept is rarely referred to in the research literature, it is not an uncommon issue raised in clinical practice. This article provides a brief overview of the literature pertaining to later-life intergenerational family estrangement, primarily between adult children and their parents. It then examines later-life family estrangement in relation to Boss's (2006) concept of ambiguous loss and Doka's (1989) ideas about disenfranchised grief. Finally, the article comments on the practice implications when working with elders experiencing family estrangement toward the end of life.
\end{abstract}

\section{IMPLICATIONS FOR PRACTICE}

- $\quad$ Practitioners should be mindful of, and responsive to, the possibility of family estrangement when working with older people.

- Practitioners should consider viewing estrangement contextually, normalizing the estrangement experience, validating associated feelings, and taking a nonjudgemental stance.

All happy families are alike; each unhappy family is unhappy in its own way. (Tolstoy, 1957, p. 1)

$\mathbf{T}$ he notion of family estrangement is probably best captured in the intimacy of myth, sacred literature, and fiction, where its depths and intricacies are given voice more readily than in the public arena. The documentation of family estrangement can be traced from the Old Testament, to the Victorian writings of George Eliot, and in more recent times, the works of J. K. Rowling. In the media, estrangement receives attention when connected to high-profile families, where it is often portrayed as an anomaly, a condition reserved for the eccentricities of the rich and famous. For example, in the United States the Astor family's business and society profile has regularly been sullied by rumors of betrayal and family estrangement (Gordon, 2006). In the political arena, Ronald and Nancy Reagan had periods of family estrangement with their children, in an often very public forum. The celebrity estrangement between performer Courtney Love and her mother Linda Carroll has also been a source of public speculation and scandal (Estroff Marano \& Perino, 2006). To a lesser degree, the media draws attention to the rare and extreme consequences of family estrangement, such as when an older person dies and their body lies undiscovered in their home for a long period of time. Family estrangement is rarely portrayed as a normal everyday occurrence.

A review of the literature in March 2009 aimed to locate material pertaining to family estrangement between adult children and their parents. Findings showed that family estrangement was rarely cited in the academic and research literature, but it was not entirely absent. The exception to the theoretical drought was the work of Dr. Murray Bowen (1913-1990) that referred to emotional cutoff, a key concept developed as a component of Bowen family systems theory. Bowen's (1978) concept of emotional cutoff has been examined by a limited number of researchers using both quantitative and qualitative methodologies, and most of these were documented in Peter Titelman's (2003) book, Emotional Cutoff: Bowen Family Systems Theory Perspectives.

Apart from Bowen (1978) and Titelman's (2003) explorations, theory about family estrangement tended to be found in the clinical rather than the academic realm. Five recently published mainstream books focused solely on estrangement. Authors included Sucov (2006) and Sichel (2004), who used their clinical and personal experiences of estrangement to examine the issue. LeBey (2001) claimed to base her book on hundreds of interviews she conducted with estranged individuals and her work with two family therapists. Davis (2002) also claimed to base her work on hundreds of interviews and her own personal experience of estrangement. Richards (2008) based her book on her personal journey of estrangement and reconciliation. In addition to these sources, estrangement was evident in some research studies, where it was not the primary phenomenon under study or the focus of the article (Fingerman, Hay, \& Birditt, 2004; McCallum, Simons, \& Simons, 2007; Peisah, Brodaty, \& Quadrio, 2006; Szydlik, 2008; Van Gaalen \& Dykstra, 2006).

Research into the nature of later-life intergenerational relationships has become increasingly sophisticated over the last three decades, and offers a foundation for understanding the estrangement phenomenon. For example, studies have consistently shown that levels of intergenerational solidarity are high, while levels of conflict are low (Bengston \& Oyama, 2007; Lowenstein, 2007; Szydlik, 2008; Van Gaalen \& Dykstra, 2006). However, studies also show that family estrangement is likely to exist in the clinical population. In Silverstein and Bengston's (1997) study, 7\% of adult children had a detached type of relationship with their mothers and $27 \%$ had this type of relationship with their fathers. The detached class is typified by an adult child's lack of engagement with parents across all solidarity indicators, and is likely to be the closest indicator to the concept of estrangement as documented in this article. Van Gaalen and Dykstra's study revealed a discordant relationship type, which comprised $4 \%$ of their sample: "Children and parents in discordant relationships are unlikely to interact or to exchange any kind of support” (p. 956). Szydlik's study found that $10 \%$ of participants reported intergenerational family conflict. Results also showed that around one third of the respondents experiencing intergenerational conflict said they ignore the issue, 
while nearly half said that they avoid the other person, or have stopped contact (Szydlik).

It is also important to consider these findings in terms of the overall limitations of research into later-life family estrangement, and implications for clinical work. Older people may be less likely to report family discord (Fingerman et al., 2004, p. 803). They tend not to report conflict with their children during therapy sessions (Beaton, Norris, \& Pratt, 2003), and in research studies they offer more positive reports of their relationships than their adult children do (Beaton et al., 2003). Krause and Rook's (2003) research into negative interactions in later life showed greater attrition of older participants who had reported negative interactions with their children. Therefore, it is imperative that researchers conduct qualitative and non-normative explorations of family estrangement, and that clinicians specifically ask older clients about possible estrangements.

Family estrangement is a unique and important issue that deserves attention. This article incorporates the currently available estrangement literature to commence dialogue about the possible effects of family estrangement on adults as they near the end of life. It examines the nature of family estrangement and comments on contemporary theories of ambiguous loss and disenfranchized grief. Informed by Erikson's developmental stage theory (Erikson, 1997; Erikson, Erikson, \& Kivnick, 1986), it presupposes that aging is a unique period for examining family estrangement, because later life requires review and integration of events that have occurred throughout the life course. Impending death may make the older individual more attuned to the estrangement, more willing to seek reconciliation with the estranged, or more likely to seek assistance in coming to terms with the loss.

\section{A Definition of Family Estrangement}

A family can be the bane of one's existence. A family can also be most of the meaning of one's existence. I don't know whether my family is bane or meaning but they have surely gone away and left a large hole in my heart. (Hulme, 1985, p. 242)

Family estrangement, or cutoff as it is sometimes referred, is the physical distancing and loss of affection between family members, often due to intense conflict or ongoing disagreement. A person may be active in the estrangement, by leaving or dismissing the family, or they may be cast out by one or more members of the family. Key indicators of an estrangement identified in the literature included physical distancing, lack of emotional intimacy, an unsatisfactory relationship, intermittent conflict and avoidance, and a belief that there is no way to resolve problems.

\section{Indicators}

Physical distancing. Direct face-to-face contact usually ceases when a family estrangement occurs (Jerrome, 1994; Sichel, 2004). The most common clinical indicator that an estrangement is present is when a client states, "We don't see each other anymore."

Lack of emotional intimacy. Sucov (2006) stated that "estrangement does not imply a lesser degree of emotional involvement; to the contrary, it is often a sign of intense, unresolved animosity" (p. 6). While there may be some perfunctory contact in some estrangements, parties do not raise any issues that have the potential to be emotionally charged or divisive (Klever, 2003). In all instances of estrangement, intimacy and trust are absent. A clinical indicator that an estrange- ment is present is when a client states, "we don't speak to each other anymore" or "I don't know her anymore, she is a stranger to me."

Relationship viewed as unsatisfactory. For an estrangement to exist, one or both parties must perceive the situation as unsatisfactory: "The sense that 'things are not as they should be' usually accompanies estrangement" (Davis, 2002, p. 13), and parties may feel sadness, loneliness, and guilt. A clinical indicator that an estrangement is present is when a client states "I wish the situation were different" or "this situation is unbearable."

Intermittent conflict and avoidance. In many families, estrangement is not a single event, but a series of conflicts followed by long periods of avoidance. As Sichel (2004) stated, estranged families "tend to vacillate between avoidance and explosiveness; they hide, avoid, and ignore difficulties and deny any real conflict until World War III breaks out" (p. 67). Sometimes estrangement results from a minor incident that bears little apparent relation to the underlying tension (Davis, 2002; LeBey, 2001). Clients may say things like, "we have been through this before" or "I had to leave to stop the fighting."

A belief that there is no resolution. Benswanger (1987) and Kelly (2003) agreed that estrangement seems to create and maintain rigid, polarized, and repetitive feelings and thought patterns. It also appears that the lack of intimacy and contact prevents each party from gaining new perspectives about the other, thus minimising the potential for reconciliation (Kelly). Clients may state things such as, "he will never change," "I will never get over his betrayal," or "it will never be the same again."

It is important to note that theorists like Bowen (1982) suggested that individuals could estrange through internal mechanisms or physical distancing, a concept some authors referred to as covert and overt cutoff or estrangement (Klever, 2003). Clinicians know that physical distance does not necessarily equate to a family estrangement, and that physical proximity does not necessarily indicate intimacy. However, in this article, estrangement will refer to overt cutoffs, where physical distancing or lack of physical contact is a primary element of the estrangement, and several (or all) of the other indicators are present.

\section{Causes of Estrangement}

While Bowen's (1982) work tended toward the adult child being the initiator of cutoff, I prefer the notion that there are multiple truths operating about the cause (and fault) of estrangement, and that no truth should be taken at face value. I believe that it takes more than one person to create and to maintain an estrangement. However, this article is written from the perspective of the older person or parent, so the discussion may inadvertently tend toward this reality.

Authors offered biological and sociopolitical explanations for family estrangement. First, it must be noted that there may be times when estrangement is a healthy response to unhealthy relationships, particularly where abuse has been, or continues to be, perpetrated by one party against another (Davis, 2002; Hargrave \& Anderson, 1997; LeBey, 2001). One of the most consistently cited challenges to the adult-child and parent relationship was the tension between connection and separateness throughout the life course (Bowen, 1982; Fingerman et al., 2004; Pillemer \& Suitor, 2002). The adult-child needs a sense of belonging within the intergenerational family, but they must also differentiate or individuate in terms of interests, pursuits, and relationships (Bedford \& Blieszner, 1997; Bowen). Excessive contact, support, and dependence have been shown to have negative effects on intergenerational relationships (Fingerman, Chen, Hay, Cichy, \& 
Lefkowitz, 2006; Ha \& Ingersoll-Dayton, 2008; Pillemer et al., 2007).

Bowen's (1978) explanation for the cause of estrangement sits primarily in the biological realm. Estrangement "is rooted in evolutionary processes that are instinctive and automatic. Cutoff functions to control and reduce anxiety generated by intense contact-stuck-together fusion-within the family of origin" (Titelman, 2003, p. 22). Bowen's key concept, differentiation of self, is the way a person manages the interplay of togetherness and individuality within the relationship system (Titelman) and assists therapists to conceptualize, and work with, "the degree of...unresolved emotional attachments to families of origin" (Bowen, 1982, p. 529). The theory suggests that individuals sit along a continuum from fusion to differentiation. Those who are least differentiated are more reactive to the emotional system (or anxiety) to the exclusion of intellect. The most highly differentiated individual will respond to anxiety with logical reasoning and decision making. Bowen (1978) was quick to point out that intellect does not equate to intelligence, but rather an ability to adapt to life's challenges in more than an instinctive fashion. Additionally, it is important to note that the word "emotional" in Bowen's work refers to instinctive, automatic responses (Illick, Hilbert-McAllister, Jefferies, \& White, 2003). An individual who is able to recognize and self-regulate emotional or instinctive responses and manage anxiety is more likely to be successful in family and social relationships and experience greater physical and emotional well-being than those who simply do "what feels right in the moment" (Bowen, 1978; Harrison, 2003; Titelman). Those who are the least differentiated are more likely to react to anxiety instinctively and are thus more likely to estrange at times of conflict.

Other authors suggested that estrangement is a response to a perceived betrayal or challenge to the family belief system (Clarke, Preston, Raksin, \& Bengston, 1999; Sichel, 2004; Sucov, 2006). Benswanger (1987) stated that "every cut-off is a reaction to the articulated or implied conviction that 'you killed my god', whether the 'god' is defined as material possessions, adequate care, or respect for a significant person, value, or belief" (p. 193). When families are more rigid, inflexible, and heavily invested in their values and beliefs, conflict and estrangement are more likely to result (Davis, 2002; Sucov). This is particularly so if the family perceives the challenge as a threat to family solidarity, identity, and survival (Benswanger; Sucov). Challenges may come in a number of political, moral, and religious forms, including family members who declare themselves to be gay or lesbian, or intending marriage to someone from another race or religion (Davis; Sucov). The challenge may be a rejection of a strongly held family value such as tertiary education or having children (Clarke et al.). Fingerman et al.'s (2006) evaluation of role centrality theory suggested that family members who identify strongly with a particular role and view it as self-defining will have more extreme responses to changes in that role. Sichel conceptualized this phenomenon in terms of individuals who challenge the "family myth." He said that the family myth is often based on the "presumption that every family member is compatible, possesses the same goals, and loves the others without question" (Sichel, p. 58). The myth is perpetuated by "we" statements about shared values and behaviours and little tolerance for individual difference. Banishing members who threaten this unity may be the only way to keep the myth intact (Sichel).

\section{A Cautionary Note}

Though some may accuse me of neglect, I have been consistent with the advice I always gave my children: never finish anything that bores you. Unfortunately, some of my children bored me.

(Haslett, 2002, p. 22)

Before proceeding to a discussion about the possible effects of later life intergenerational family estrangement, it is important to reconsider human variance. It is highly possible that estrangement has a minimal effect on some older people's quality of life. It is also possible that family estrangement is a highly traumatic event that leads to negative symptomatology for some older people.

\section{Ambiguous Loss}

Piglet sidled up to Pooh from behind. "Pooh!" he whispered. "Yes, Piglet?" "Nothing," said Piglet, taking Pooh's paw. "I just wanted to be sure of you." (A. A. Milne)

Pauline Boss coined the term ambiguous loss in 1975. This term described a specific type of phenomenological loss that she was encountering in her work as a family therapist (Boss, 2006). The theory of ambiguous loss has continued to be developed and it has been applied as a theoretical concept across numerous areas of research, including divorce, infertility, incarceration, missing persons, and immigration (Boss). It does not appear to have been applied to the concept of laterlife intergenerational estrangement.

Ambiguous loss is essentially a confused state of whether there is an absence or presence of another. Boss (2006) described two types of losses that characterize ambiguous loss: physically present but psychologically absent, or physically absent but still psychologically present in the mind of the person experiencing the loss of the other. Estrangement, as conceptualized in this article, relates primarily to the latter, an overt situation where family members are physically and emotionally distanced from one another, but a complex interplay of psychological and social factors keep the estranged member psychologically present. As stated previously, the cause, duration, and potential for reconciliation of the estrangement is often unknown or ambiguous. Additionally, people experiencing the loss often become confused about the roles and status of themselves and of others in their social system and they don't know how to act or what to do. Boss has named this boundary ambiguity.

Ambiguous loss is described as the most stressful kind of loss, which results in an inability to resolve the loss as well as long term confusion around who is in or out of a family system. Loss coupled with ambiguity (unsureness, fogginess, lack of clarity) creates a powerful barrier to coping and grieving. The difficulties in resolving the loss can therefore lead to a situation of chronic loss. There already exists a societal expectation that a bereaved person will "get over a loss," however in the case of ambiguous loss there is often no official recognition of the loss, therefore finding closure is virtually impossible (Boss, 2006). Sichel (2007) concurred, stating that

the trauma of a family member physically dying usually becomes less painful with time-it falls under the heading of a natural catastrophe from which the human psyche ultimately learns to heal. However, on two decades of evidence of the scores of my patients who've faced both kinds of trauma, the psychological death of a family cutoff clearly tends to remain torturous-and very much more emotionally damaging. (p. 2) 
Boss's (2006) recognition of the situational and societal factors that impact loss and grief were supported by Doka's (1989) conceptualization of disenfranchized grief. Doka's definition: “disenfranchised grief is the grief that persons experience when they incur a loss that is not or cannot be openly acknowledged, publicly mourned, or socially supported" (Corr, 2002, p. 39). Doka argued that grief can be disenfranchized in three ways: the relationship is not recognized, the loss is not recognized, and/or the griever is not recognized. When grief is disenfranchized, those who experience the loss are forbidden to grieve, their sources of support are minimized, and opportunities to access or take part in rituals are denied (Corr).

\section{Case Example}

Elizabeth is a 68-year-old woman who lives with her disabled son, Toby. She has been estranged from her eldest son, Jarrad, since her divorce from his father, 24 years earlier. Jarrad blamed Elizabeth for the divorce and told her that he no longer wished to have contact. Initially, Elizabeth posted birthday and Christmas cards to the family home in the hope that Jarrad would contact her, but she never received a response. After 10 years Elizabeth decided it was time to stop sending the cards and she moved to a new area to make a fresh start. Elizabeth made new friends and created a satisfying life, but she never mentioned her eldest son, because "people just wouldn't understand-how can I explain that my own son doesn't talk to me?" Twelve months ago, Elizabeth was diagnosed with cancer. When the social worker spoke to Elizabeth, the estrangement story emerged as a difficult part of receiving the cancer diagnosis. Elizabeth had started to ruminate about the lost relationship with her son. She wondered whether she should have told him about the emotional abuse she had received from her husband and explained her side of the "divorce story." She secretly hoped that Jarrad might find out that she was ill and that he would come to visit her. She wondered what would happen to Toby if she died and whether Jarrad would take some responsibility for his future care. She became distressed about her inability to make things right with Jarrad. Elizabeth even started to question her previous decision to cut Jarrad from her will, saying "after all, he is my son."

\section{Family Estrangement: A Unique Type of Loss}

Family estrangement is a type of ambiguous loss, and it often results in ambivalence, role ambiguity, and disenfranchised grief. The estranged person's concept of the loss remains ambiguous in that the person holds two opposing ideas simultaneously: that the estranged person is coming back-but maybe not. For example, there may be a belief that the adult child will return, and that reconciliation will eventuate before the parent's death. Like Elizabeth, some older people have a deeply held belief that their child will return before their death. In reality, parties may have lost all knowledge of each others' whereabouts, and family members may not feel it is their place to pass on information about the ailing older person. The older person may be ambivalent about the estrangement, simultaneously feeling love and hate for the estranged member, and maybe even vacillating between wishing them dead and wishing them back in the family system. We see this dichotomy play out in Elizabeth's dilemma about her will. In a symbolic gesture, Elizabeth has cut Jarrad out of her will (and her life), but she also starts to question this decision when there is a possibility that he may return. The uncertainty about the state of the relationship may lead to role ambiguity, where other family members are unsure about who is in or out of the family, and what roles should be assumed or left vacant. For example, extended family members may not wish to offend an older person by assuming a role or duty previously carried out by the estranged adult child. In the case example, the role of Toby's potential carer is left vacant or unaddressed. In addition, the grief associated with family estrangement is disenfranchised, never fully recognised by society, due to its inconclusiveness, and the social stigma associated with its admission. In the case example, Elizabeth refrains from speaking to her new friends about her son Jarrad for fear of their disapproval, but this also prevents her from receiving their support or understanding her distress when she is ill. There are a number of factors that make this loss unique.

Types of relationship. Intergenerational relationships are involuntary relationships, that are "embedded within and influenced by a kinship system of relationships that span generations of members both living and dead" (Bedford \& Blieszner, 1997, p. 527). They are generally the longest, and arguably the most important, relationships that exist throughout the lifespan. Increasing longevity means that 21 st century kinship bonds are likely to last for more years than at any other time in history (Van Gaalen \& Dykstra, 2006). The significant majority of the adult-child relationship is experienced when both generations are in adulthood, often a period of over 40 years (Cherlin, 2008).

Socioemotional selectivity theory suggests that older people reduce their social networks as they age, shifting their allegiance to a core group comprising primarily of kin (Krause \& Rook, 2003). Intergenerational kinship relationships are difficult to replace compared to purely voluntary relationships with friends and acquaintances (Fingerman et al., 2004; Krause \& Rook, 2003). Neyer and Lang's (2003) research showed that kin remain the most important source of emotional and instrumental support in later life. While social support, which is generally based on reciprocity, can be sourced from a variety of relationships if necessary, "people give more weight to kinship in awkward and emergency situations" (Neyer \& Lang, p. 318). When an adult child is estranged this lessens or removes a unique type of support available to the older person.

Societal norms and expectations. Intergenerational relationships are also subject to an interplay of sentiment, ascribed social meanings, and expectations. There are societal norms about good parenting and good families and family estrangement does not fit with these. This may impact on an older person's sense of self and life achievement. For example, a parent may not speak of their estranged adult child, fearing judgements about their parenting or their contribution to the estrangement. As Sichel (2007) noted, this trauma is not caused by natural catastrophe, "it's the design of members of your own family: the very people you thought loved you most in the world. That isn't something you're likely to broadcast-or even tell most of your best friends in private" (p. 3, emphasis in original). Jerrome's (1994) study found that many older people explained their estranged child's absence in terms of "busyness," something their peers saw more socially acceptable than abandonment. When one tries to hide or disguise their child's estrangement, the loss is further disenfranchised.

Intergenerational implications. Bowen's (1978) theory suggested that family estrangement runs in families. First, estrangements may be passed on from one generation to the next. A parent who is estranged from particular family members will usually keep their children away, so grandparents may lose the opportunity to build relationships with grandchildren. Second, Bowen believed that emotional attachment patterns, or a multigenerational transmission process, such as the ways parents coped with critical periods of anxiety, had considerable influence on future generational patterns. When families estrange they lose some of their support system, meaning that 
they may need to rely on the immediate members more acutely. This dependence can itself create additional anxiety and confusion, and may contribute to further estrangements.

"As parents age and die, loyalties and lines of allegiance often shift within a family. The death (or impending death) of a parent can bring siblings together or split them apart" (Davis, 2002, p. 143). The requirements of caring for an older parent may bring latent childhood sibling rivalry to the fore (LeBey, 2001; Schulman, 1999). Later life also brings the complications of inheritances. For those left behind, and despite the amount of money and property involved, an inheritance can be a symbolic transaction of power, love, loyalty, and favour (LeBey; Sucov, 2006), as well as a source of intergenerational tension. A particular contributor to conflict, uncovered in two recent studies, was the reappearance (and reported interference) of previously estranged family members when the older person's health status changed (Kramer, Boelk, \& Auer, 2006; Neufield \& Harrison, 2003). Peisah et al. (2006) conducted a thematic analysis of 50 cases involving an older person with dementia that required dispute resolution before the Guardianship Tribunal in Australia. They uncovered numerous cases of laterlife family estrangement, often fuelled by the older person's paranoid delusions and latent sibling rivalry. The ensuing conflict and estrangement was often played out through sibling and parental accusations of neglect and financial exploitation of the older person (Peisah et al.). All of these factors have the potential to create new, and maintain old, family estrangements.

Own contribution to the loss. Estrangement carries with it the idea that one or both parties could have done something differently, and ownership of this belief may be linked to guilt and lowered emotional well-being. In some cases, the person who has been estranged may not have been informed of the reason for the estrangement, so they do not know where to begin to examine the situation, let alone find a resolution or deal with their guilt.

Multiple losses. From the aforementioned conditions, we can anticipate that estrangement has potential impacts on many areas of later-life well-being. Quality of life indicators include domains such as emotional well-being, interpersonal relations, material well-being, personal development, physical well-being, self-determination, social inclusion, and rights (Schalock \& Alonso, 2002). It is likely that family estrangement could impact all of these domains in different ways and at different times, so it is important to consider all of the possible effects of estrangement when working with older people who are no longer on speaking terms with one or more members of their family.

\section{Practice Implications}

Before proceeding to a discussion about the ways of working with elders experiencing family estrangement, it is also important to consider this in terms of Neimeyer and Currier's (2008) review of the effectiveness of grief therapy, which suggests that universal interventions for grieving clients are minimally effective, whereas focusing on indicated clients- "those who show heightened or prolonged distress that compromises their daily functioning" (p. 18)-produces greater results. As previously alluded to, no specific, clear model of clinical practice intervention has been devised or put forward in relation to working with and supporting older people adversely affected by family estrangement. Further, no models or strategies have been empirically researched for their actual and potential effectiveness in working with this client group. As previously mentioned, ambiguous loss can be used to explain the losses that may be felt by older people experi- encing estrangement. One situation where ambiguous loss has been applied is in the area of missing persons. Some of the principles of working with families and friends of missing persons may be used to inform practice with older people experiencing estrangement (Families \& Friends of Missing Persons Unit, 2001).

\section{Intervention Strategies}

A number of principles for clinical practice and intervention could be devised by looking at the five key indictors of estrangement identified in the literature and already outlined in this article: physical distancing, lack of emotional intimacy, the relationship being viewed as unsatisfactory, intermittent conflict and avoidance, and a belief in there being no resolution in the situation. By looking at these five indicators and the impact they may have on individuals seeking professional input and support, we could devise potential assessment areas and intervention strategies for our work with older people in any context.

However, as already stated, it will be important to assess for the specific impact of the estrangement on the individual and implement support and intervention strategies based on these effects. This is suggested as opposed to implementing a set model for responding to the estrangement of a family member, which could be based on assumptions about the effects that this loss or separation may have on the older person. As such, some general intervention strategies and good practice points for working with older people experiencing estrangement might be the following.

Ask key assessment questions. Inquire about possible estrangement and the impact this may be having on the older person's physical and psychological well-being. Given that the literature indicates elderly people are unlikely to mention an estrangement or cutoff with a family member (Mancini \& Blieszner in Beaton et al., 2003), it will be important for health professionals to ask appropriate and empathic questions around this area in any comprehensive psychosocial assessment being undertaken with the older person. This part of an assessment could be undertaken in regard to questioning about significant relationships — both past and present—-to see if an older person defines the status of any of these relationships as currently unsatisfactory.

Employ a nonjudgmental approach to practice. Ensure an environment where an older person would feel comfortable to disclose a family estrangement and therefore talk about the impact it may be having on their life.

Normalize the estrangement experience or situation. At the very least, acknowledge the emotions and feelings of the older person that are arising from that estrangement. If a sense of loss is being experienced and reported it may be important for the older person to hear these experiences being given a name: "Those suffering from ambiguous loss are often surprised and visibly relieved to hear that their distress has a name" (Boss \& Couden, 2002, p. 1354).

Validate the feelings of loss. This is in line with a nonjudgmental approach to practice, and even the positive emotions that older people might report (such as relief) will be important.

Understand clients in context. "You need to discover the contextual frameworks that can help you understand your clients as 'people in systems"' (Egan, 2007, p. 90). In order for this to occur, the clinician needs to be able to look at the individual context and also evaluate the impact of the estrangement in relation to their family system. For example, it may be the case that estrangement is seen as a normal occurrence in this family system, and as such would not necessarily carry with it such negative effects and connotations for the older person. It might also be the case that the estrangement has operated as a 
survival function for the family and that without the boundary that the estrangement provides, the family system may have deteriorated significantly further. Left intact, the family system may have developed symptoms such as child abuse and neglect.

Consider the developmental stage of the client. In the case of an older person, and in line with Erikson's developmental stages (Erikson, 1986; Erikson et al., 1997), it will be important to evaluate and listen for the impact of the estrangement on their well-being as they move toward the end of their life.

Focus on the effects of the stressor. It is important for health professionals to target effects (e.g., the estrangement) as opposed to final resolutions of the loss. In this way, it is the impacts of the estrangement on the older person that are addressed and worked on as opposed to seeking a final resolution to the estrangement, which may be out of the control of the older person.

\section{Conclusion}

While the accuracy of empirical data about family estrangement is debatable, the experience of later family estrangement is undeniable. Clinicians do work with older clients who are no longer on speaking terms with one or more adult child. For some older people, this is a matter of fact; for others, a source of great pain and rumination. Boss (2006) and Doka (1989) offer insight into the processes that may exacerbate the effects of family estrangement on some older people, and highlight the complexity of clinical work with this population. While this article offers some beginning thoughts about practice implications, it is imperative that additional research is carried out into the incidence, causes, and effects of family estrangement, as well as possible interventions with those experiencing negative effects at the end of life.

\section{References}

Beaton, J. M., Norris, J. E., \& Pratt, M. W. (2003). Unresolved issues in adult children's marital relationships involving intergenerational problems. Family Relations, 52(2), 143-153.

Bedford, V. H., \& Blieszner, R. (1997). Personal relationships in later-life families. In S. Duck (Ed.), Handbook of personal relationships. Chichester, West Sussex: John Wiley \& Sons.

Bengston, V. L., \& Oyama, P. S. (2007). Intergenerational solidarity: Strengthening economic and social ties. New York: United Nations Headquarters.

Benswanger, E. G. (1987). Strategies to explore cut-offs. In P. Titelman (Ed.), The therapist's own family: toward the differentiation of self (pp. 191-208). Northvale, New Jersey: Jason Aronson.

Boss, P. (2006). Loss, trauma and resilience: Therapeutic work with ambiguous loss. New York: W. W. Norton.

Boss, P., \& Couden, B. A. (2002). Ambiguous loss from chronic illness: Clinical interventions with individuals, couples, and families. JCLP/In Session: Psychotherapy in Practice, 58(11), 1351-1360.

Bowen, M. (1978). Family therapy in clinical practice. New York: Jason Aronson.

Bowen, M. (1982). Family therapy in clinical practice (2nd ed.). New York: Jason Aronson.

Cherlin, A. J. (2008). Public and private families: An introduction (5th ed.). Boston: McGraw Hill.

Clarke, E. J., Preston, M., Raksin, J., \& Bengston, V. L. (1999). Types of conflicts and tensions between older parents and adult children. The Gerontologist, 39(3), 261-270.

Corr, C. A. (2002). Revisiting the concept of disenfranchised grief. In K. J. Doka (Ed.), Disenfranchised Grief: New directions, challenges and strategies for practice. Illinois: Research Press.

Davis, L. (2002). I thought we'd never speak again: The road from estrangement to reconciliation. New York: Quill.

Doka, K. J. (1989). Disenfranchised grief: Recognizing hidden sorrow. Lexington, MA: Lexington Press.

Egan, G. (2007). The skilled helper: A problem management and opportunity development approach to helping (8th ed.). Belmont, California: Brooks/Cole.
Erikson, E. H. (1997). The lifecycle completed. New York: W. W. Norton.

Erikson, E. H., Erikson, J. M., \& Kivnick, H. Q. (1986). Vital involvement in old age New York: W. W. Norton.

Estroff Marano, H., \& Perino, K. (2006). Tortured love: Linda Carroll's unorthodox relationship with her famous mother and infamous daughter forced her to reevaluate love, loss and the control we have over the people we most want to protect. Psychology Today, 39(4), 94-102.

Fingerman, K. L., Chen, P., Hay, E., Cichy, K. E., \& Lefkowitz, E. S. (2006). Ambivalent reactions in the parent and offspring relationship. The Journals of Gerontology, 61B(3), 152-161.

Fingerman, K. L., Hay, E. L., \& Birditt, K. S. (2004). The best of ties, the worst of ties: Close, problematic and ambivalent social relationships. Journal of Marriage and Family, 66(3), 792-808.

Families \& Friends of Missing Persons Unit. (2001). "It's the hope that hurts": Best practice in counselling models relevant to families and friends of missing persons. Newcastle, NSW: Hunter Institute of Mental Health.

Gordon, M. (2006, August 14). The family Astor: the Brooke Astor scandal may be a tale of elder abuse. But it's also just another sad chapter in the family's history of parental estrangement. New York, 38-43.

Ha, J., \& Ingersoll-Dayton, B. (2008). The effect of widowhood on intergenerational ambivalence. The Journals of Gerontology: Series B, 63(1), 49-58.

Hargrave, T. D., \& Anderson, W. T. (1997). Finishing well: A contextual family therapy approach to the aging family. In T. D. Hargrave \& S. M. Hanna (Eds.), The aging family: new visions in theory, practice, and reality (pp. 61-80). New York: Brunner/Mazel.

Harrison, V. (2003). Reproduction and emotional cutoff. In P. Titelman (Ed.), Emotional cutoff: Bowen family systems theory perspectives (pp. 245-272). New York: The Haworth Clinical Practice Press.

Haslett, A. (2002). You are not a stranger here. New York: Anchor Books.

Hulme, K. (1985). The bone people. Auckland: Spiral.

Illick, S. D., Hilbert-McAllister, G., Jefferies, S. E., \& White, C. M. (2003). Toward understanding and measuring emotional cutoff. In P. Titelman (Ed.), Emotional cutoff: Bowen family systems theory perspectives (pp. 199-218). New York: Haworth Clinical Practice Press.

Jerrome, D. (1994). Family estrangement: Parents and children who 'lose touch'. The Journal of Family Therapy, 16(3), 241-258.

Kelly, B. J. (2003). Toward undoing cutoff: A twenty-five-year perspective. In P. Titelman (Ed.), Emotional cutoff: Bowen family systems theory perspectives (pp. 139-158). New York: Haworth Clinical Practice Press.

Klever, P. (2003). Marital functioning and multigenerational fusion and cutoff. In P. Titelman (Ed.), Emotional cutoff: Bowen family systems theory perspectives (pp. 219-244). New York: Haworth Clinical Practice Press.

Kramer, B. J., Boelk, A. Z., \& Auer, C. (2006). Family conflict at the end of life: Lessons learned in a model program for vulnerable older adults. Journal of Palliative Medicine, 9(3), 791-801.

Krause, N., \& Rook, K. S. (2003). Negative interaction in late life: Issues in the stability and generalizability of conflict across relationships. Journal of Gerontology, 58B(2), 88-99.

LeBey, B. (2001). Family estrangements: How they begin, how to mend them, how to cope with them. Atlanta: Longstreet Press.

Lowenstein, A. (2007). Solidarity-conflict and ambivalence: Testing two conceptual frameworks and their impact on quality of life for older family members. Jour nal of Gerontology, 62B(2), S100-S107.

McCallum, J., Simons, L. A., \& Simons, J. (2007). Private lives and public programs: An Australian longitudinal study of the elderly. Journal of Aging and Social Policy, 19(4), 87-104

Neimeyer, R. A., \& Currier, J. M. (2008). Bereavement interventions: Present status and future horizons. Grief Matters, 11(1), 18-22.

Neufield, A., \& Harrison, M. J. (2003). Unfulfilled expectations and negative interactions: Nonsupport in the relationships of women caregivers. Journal of Advanced Nursing, 41(4), 323-331.

Neyer, F. J., \& Lang, F. R. (2003). Blood is thicker than water: Kinship orientation across adulthood. Journal of Personality and Social Psychology, 84(2), 310-321.

Peisah, C., Brodaty, H., \& Quadrio, C. (2006). Family conflict in dementia: Prodigal sons and black sheep. International Journal of Geriatric Psychiatry, 21(5), 485-492.

Pillemer, K., \& Suitor, J. J. (2002). Explaining mother's ambivalence toward their adult children. Journal of Marriage and Family, 64(3), 602-613.

Pillemer, K., Suitor, J. J., Mock, S. E., Sabir, M., Pardo, T. B., \& Sechrist, J. (2007). Capturing the complexity of intergenerational relations: Exploring ambivalence within later life families. Journal of Social Issues, 63(4), 775-791.

Richards, N. (2008). Heal and forgive II: The journey from abuse and estrangement to reconciliation. Nevada City, NV: Blue Dolphin Publishing.

Schalock, R., \& Alonso, M. A. V. (2002). Handbook on quality of life for human service practitioners. Washingston, DC: American Association for Mental Retardation. 
Schulman, G. L. (1999). Siblings revisited: Old conflicts and new opportunities in later life. Journal of Marital and Family Therapy, 25(4), 517-525.

Sichel, M. (2004). Healing from family rifts: Ten steps to finding peace after being cut off from a family member. New York: McGraw Hill.

Sichel, M. (2007). Estranged family: Dealing with a family rift. Retrieved August 23, 2009, from http://www.sideroad.com/Family_Life/estranged-family.html

Silverstein, M., \& Bengston, V. L. (1997). Intergenerational solidarity and the structure of adult child-parent relationships in American families. American Journal of Sociology, 103(2), 429-460.

Sucov, E. B. (2006). Fragmented families: Patterns of estrangement and reconciliation. Jerusalem, Israel: Southern Hills Press.

Szydlik, M. (2008). Intergenerational solidarity and conflict. Journal of Comparative Family Studies, 39(1), 97-118.

Titelman, P. (2003). Emotional cutoff in Bowen family systems theory: An overview. In P. Titelman (Ed.), Emotional cutoff: Bowen family systems theory perspectives (pp. 9-66). New York: Haworth Clinical Practice Press.

Titelman, P. (Ed.). (2003). Emotional cutoff: Bowen family systems theory perspectives. New York: Haworth Clinical Practice Press.

Tolstoy, L. (1957). Anna Karenina. London: Penguin.

Van Gaalen, R. I., \& Dykstra, P. A. (2006). Solidarity and conflict between adult children and parents: A latent class analysis. Journal of Marriage and Family, 68(4), 947-960.

Kylie Agllias, BSW (Hons), lecturer in social work, University of Newcastle. Correspondence: Kylie.Agllias@newcastle.edu.au; School of Humanities and Social Science, University of Newcastle, University Drive, Callaghan 2308, Australia.

Author's note. I would like to thank Karen Barrett for her thoughtful and generous input into the practice implications in this article, as well as Mel Gray and Jill Gibbons for their ongoing support.

Manuscript submitted: July 14, 2009

Revised: October 8, 2009

Accepted: October 16, 2009 